\title{
A Case Report of Borderline Personality Disorder
}

\author{
Fatema Zohra* \\ Bangabandhu Sheikh Mujib Medical University, South Asia
}

Submission: October 10, 2018; Published: October 25, 2018

*Corresponding author: Fatema Zohra MD, Bangabandhu Sheikh Mujib Medical University, South Asia; Email: cn_bihs_2012@yahoo.com

\begin{abstract}
A 22 years old girl came to National Institute of Mental Health with her mother with the complaints of history of repeated self-injurious behavior, aggressive behavior towards family members, feeling of emptiness, lack of interest to all activity \& sleep disturbance. These symptoms started for last two years after she completed her Higher Secondary Certificate (HSC) exam. Family environment was described by the patient as very chaotic, hostile $\&$ distressful. Family rules were harsh, rigid \& inconsistent. There was poor bonding with her father. History of parental confrontation \& wrangling in early childhood. On mental state examination she was cooperative, coherent, kempt. She wanted a cigarette from the interviewer during interview. Her speech was well organized. She was generally dysphoric with a constricted affect, had persecutory delusion but no suicidal ideation, no abnormal perception. Based on history \& mental state examination she was diagnosed as a case of borderline personality disorder with co morbid depression. Both pharmacological \& psychological treatment were given to manage the case.
\end{abstract}

\section{Case Presentation}

A 22 years old girl, unmarried, student of BSc hons $2^{\text {nd }}$ year, hailing from urban background, came to National Institute of Mental Health with her mother with the complaints of history of repeated self-injurious behavior, aggressive behavior towards family members, feeling of emptiness, lack of interest to all activity \& sleep disturbance. Patient $\&$ her mother stated that patient was reasonably well three years back. Her problem started after she completed her HSC exam. It started with history of repeated selfinjurious behavior like cutting her own hands by blade, taking sedatives, try to hang herself. All incidents were happened after quarrel with her friends or family members.

She was very short tempered, demanding, reckless, irritable, occasional aggressive. She had difficulty to control her anger \& intense emotional fluctuation. Relationship with her friends \& family were not good. She was a good student but her academic performance gradually became deteriorated. She had started with multiple relationship with different boys but those were very superficial. She had feeling of insecurity \& fear of rejection. So, she never made those relationship very close. Those events made her lonelier. She was feeling empty inside her own. According to her mother she has ran away from home several times \& lived with his boyfriend's house. She tried to show people that she was very happy \& a smart girl. So, she demands money from her parents \& sometimes from her friends \& boyfriends.

Regarding her family history she belonged to a middle-class family. The family environment was described by the patient as very chaotic., hostile \& distressful. Family rules were harsh, rigid $\&$ inconsistent. There was poor bonding with her father. History of parental confrontation \& wrangling in early childhood. She took treatment from psychiatrist previously \& had been hospitalized for herself injurious behavior. She also had history of drug noncompliance. Because she believed that her mother has given those drugs intentionally \& her family is the main reason for her relationship breakup. She was a smoker \& occasional drinker of alcohol. She took this for relieving her distress. She also had low mood that remain most of the day. She felt no interest to do her activity. She had sleep disturbance. She could not sleep at night because she continuously thought about her past events. She can only sleep for 2-3 hours at night \& woke up early in the morning but did not feel refreshing.

On interviewing, she was cooperative, coherent, kempt, cooled, wearing salwar kamiz which was culturally \& socially appropriate, no psychomotor abnormality. She wanted a cigarette from the interviewer during interview. Her speech was well organized. She was generally dysphoric with a constricted affect, had persecutory delusion but no suicidal ideation, no abnormal perception, attention was focused but not sustained. Diagnosis of borderline personality disorder with co morbid depression was done by history, physical \& mental state examination, physical investigations \& psychological intervention. All baseline investigations with special investigations reports were normal.

To manage this patient both pharmacological \& psychological treatment were given. To prevent further suicidal attempt advised her mother to hospitalized her. But she refused. Then pharmacological treatment was given. Selective serotonin reuptake inhibitor (SSRI), mood stabilizer (Lithium), low dose 


\section{Psychology and Behavioral Science International Journal}

antipsychotic (Olanzapine) were given. Psychological treatment was given to prevent further suicidal attempt. Advice given to her mother that she must keep away all sharp weapons, sedatives, not allow the patient to take her medicine alone, not allow her to stay alone in room \& go to bathroom. Group therapy was advised to learn how interact with others \& how to effectively express herself. Dialectical behavior therapy was given to control intense emotion, reduce self-destructive behavior, improve relationship. Cognitive behavior therapy was given to identify \& change core belief, reduce ranges of mood changes \& anxiety. Advised her for regular follow up \& continue psychotherapy.

\section{Discussion}

Borderline personality disorder (BPD) is one of the cluster B type of personality disorder. It is common in psychiatric setting with a reported prevalence of $20 \%$ [1]. In BPD co morbid depression, anxiety spectrum disorders \& bipolar illness occur more frequently \& the lifetime risk of having at least one co morbid mental disorder approaches $100 \%$ [2]. It is more common in women, higher in urban population. It was originally used in psychodramatic circles to describe people with a marked instability. Kernberg [3] described it as involving ego weakness with poor control of impulses, irrational thinking despite intact reality testing. He postulated that difficulties in the Mahlerian stage of separation individuation during childhood lead to internalized object relations deficits, in that there is impairment of the essential task of the ego regarding differentiating self from external objects \& integrating self \& object under the influence of libidinal \& aggressive derivatives. He states that this lack of integrated selfconcept \& of the relationship of self with objects results in what Erikson called Identity diffusion. Buie and Adler relate that the fundamental psychopathology in Borderline personality disorder involves annihilation anxiety because of inadequacy \& instability of holding soothing introjects with an inability to internalize real caring relationships necessary for the development of these introjects. These core developmental deficits are that which need repair to treat the borderline personality disorder $[4,5]$.

Although it is classified as a personality disorder, several symptoms of BPD may intuitively respond to drug treatment. These include affective instability, transient stress related psychotic symptoms, suicidal \& self-harming behaviors \& impulsivity [6]. They have strong \& fluctuating emotion. Use of less mature defense mechanism such as projection \& deniel \& diffuse personal identity. They strive for affection \& intimacy but are regularly disappointed \& may exhaust their parents with the intensity of their emotional demand. They have unpredictable mood \& feeling of insecurity about their personal identity. Selfdestructive behavior or self-harm is common \& can be extreme \& dominate the relationship with care service. Alcohol \& drug abuse are also common because they attempt to blunt their distressing emotion.

It occurs more commonly in women. They have a pervasive pattern of instable interpersonal relationship, self-image \& affects $\&$ marked impulsivity beginning by early adulthood \& present in a variety of context characterized by alternating between extreme of idealization \& devaluation. There are frantic efforts to avoid real or imagined abandonment. Impulsivity occurs at least two areas that are potentially self-damaging (that is spending, sex, substance abuse, reckless driving, binge eating, recurrent suicidal behavior, gesture or threats or self-mutilating behavior), affective instability is present due to marked reactivity of mood.

Genetic factors are important. First degree relatives of borderline personality disorder are 10 times more likely to be treated for borderline personality disorder. Some studies reveled that on imaging, subtle gray matter changes in prefrontal \& limbic region as well as functional dysregulation of cortico- limbic circuitry involved in emotional dysregulation. Psychodynamic theory proposes a disturbed relationship with the mother \& her child. Some reports that experienced physical, emotional \& sexual abuse in childhood Bereloicz \& Tarnopolsky. Readmission of hospital needed if someone has repeated suicidal attempt. Common precipitating stresses are relationship problem, parental rejection. Stressor may be recurrent. Some patients may meet the criteria for both personality disorder \& adjustment disorder. Five common characteristics of evidence-based treatment are structured approach to prototypic borderline personality disorder problems. Patients are encouraged to assume control of themselves. Therapist helps to correction of feelings to events \& action \& discuss cases including personal reaction with others.

To diagnose borderline personality disorder \& treat it is very difficult because according to Perry \& Klerman, in their review of diagnostic criteria based on writings of Knight, Kemberg, Grinker, Gunderson \& Singer concluded that in borderline patients it seems as if the whole range of psychopathology of personality is represented [7]. This is one likely reason that their treatment is difficult. Gunderson as well as Davis Akiska have proposed that the borderline personality disorder probably represents a heterogenous disorder for which no single pharmacological treatment seems uniformly effective but for which various psychotropic agents including TCA \& MAOI antidepressants, neuroleptics, anxiolytics \& lithium have been employed depending on the presenting target symptoms $[7,8]$.

A high proportion of people with BPD are prescribed psychotropic drugs often in polypharmacy regimen. Indeed, a recent survey of practicing across England found that over $90 \%$ of the patients with BPD have been prescribed psychotropic medications most commonly antidepressants or antipsychotics particularly for affective instability [9]. In 2009 NICE recommended that drug treatment should not be used routinely for BPD, drug treatment may be considered for co morbid illness, short term use of sedative medication may be considered for people with BPD in a crisis. The duration of treatment should not be longer than one week [10]. NICE guidelines were last reviewed in January 2015 when no changes were recommended.

\section{Conclusion}

Proposed characteristics for a generalist approach to treat borderline personality disorder are treatment providers have 


\section{Psychology and Behavioral Science International Journal}

previous experience with borderline personality disorder, focusing on managing life situations non-intensively that is once per week. Additional sessions are needed. Group \& family interventions are encouraged when necessary.

\section{References}

1. Kernberg OF (2009) Borderline personality disorder. American psychiatry 166: 505-508.

2. Pascual JC, Martín Blanco A, Soler J, Ferrer A, Tiana T, et al. (2010) A naturalistic study of changes in pharmacological prescription for borderline personality disorder in clinical practice: from APA to NICE guidelines. Int Clin Psychopharmacol 25(6): 349-355.

3. Kernberg O (1975) Borderline Conditions and Pathological Narcissism New York J Aronson, New York.

4. Paul Harrison, Philip Cowen (2018) Shorter oxford textbook of Psychiatry. ( $7^{\text {th }}$ edn.), Personality disorder: Borderline personality disorder 7: 400
5. Buie D, Adler G (1982) The definitive treatment of the borderline personality. Int J Psychoanal Psychother 9: 51-87.

6. Oldham JM (2005) Guideline watch: Practice guideline for the treatment of Patients with Borderline Personality Disorder. Focus 3: $396-400$

7. Gunderson J (1985) The interface between borderline personality disorder \& affective disorder. Am J Psychiatry 142: 277-288.

8. Davis G, Akiskal H (1986) Descriptive, biological and theoretical aspects of borderline personality disorder. Hospital \& Community psychiatry 37: 685-692.

9. Paton C (2015) Prescribing for people with emotionally unstable personality disorder under the care of UK mental health service. J Clin Psychiatry 76: e512-518.

10. (2009) Borderline personality Disorder: recognition \& management Clinical Guideline p: 1-30.

\section{Your next submission with Juniper Publishers will reach you the below assets}

- Quality Editorial service

- Swift Peer Review

- Reprints availability

- E-prints Service

- Manuscript Podcast for convenient understanding

- Global attainment for your research

- Manuscript accessibility in different formats

( Pdf, E-pub, Full Text, Audio)

- Unceasing customer service

Track the below URL for one-step submission

https://juniperpublishers.com/online-submission.php 